\title{
Ultra-High Temperature Interaction Between h-BN-Based Composite and Molten Silicon
}

\author{
WOJCIECH POLKOWSKI, NATALIA SOBCZAK, ADELAJDA POLKOWSKA, \\ RAFAŁ NOWAK, ARTUR KUDYBA, GRZEGORZ BRUZDA, \\ DONATELLA GIURANNO, AMANDA GENEROSI, BARBARA PACI, \\ and DANIELE M. TRUCCHI
}

\begin{abstract}
Silicon has been recently proposed as a very promising phase change material for applications in latent heat thermal energy storage (LHTES) and conversion systems working at ultra-high temperatures. However, in order to successfully develop such kind of devices, suitable refractories showing low reactivity and non-wetting behavior upon the melting and storing of molten silicon at temperatures much higher than its melting point have to be selected. In our previous work, we have documented that the non-wetting behavior in $\mathrm{Si} / \mathrm{h}-\mathrm{BN}$ system is preserved at temperatures up to $1650^{\circ} \mathrm{C}$, with the absence of new reaction products formed at the interface. These findings make hexagonal boron nitride (h-BN) a reasonable first candidate for Si-based LHTES applications. Nevertheless, the rather poor mechanical strength of "pure" h-BN ought to be improved in order to enhance the reliability under thermocycling operational conditions and to increase the life period of the device. Therefore, in the present paper, we examine for the first time the interactions at ultra-high temperatures between a high strength commercial h-BN-based composite and molten Si. At temperatures up to $1750{ }^{\circ} \mathrm{C}$, the wettability of the h-BN-based composite (h-BN $+\mathrm{SiC}+\mathrm{ZrO}_{2}$ ) with molten $\mathrm{Si}$ is much lower if compared to the pure h-BN counterpart. Additionally, the role of reinforcements $\left(\mathrm{SiC}+\mathrm{ZrO}_{2}\right)$ and occured microstructural evolution is discussed based on the results obtained by SEM and XRD analyses.
\end{abstract}

https://doi.org/10.1007/s11661-018-5035-z

(c) The Author(s) 2018

\section{INTRODUCTION}

BY taking into account ecological, economical and geopolitical concerns of the energy resources and their accessibility, concentrated solar power (CSP) has been widely recognized as one of the most promising renewable energy sources. However, the lack of energy supply during sunless periods generates an urgent need to develop efficient energy storage methods to cover the gap existing between energy production and

WOJCIECH POLKOWSKI, ADELAJDA POLKOWSKA, RAFAI NOWAK, ARTUR KUDYBA, and GRZEGORZ BRUZDA are with the Foundry Research Institute, Zakopiańska 73 Str., 30-426 Krakow, Poland. Contact e-mail: wojciech.polkowski@iod.krakow.pl NATALIA SOBCZAK is with the Foundry Research Institute and also with the Institute of Precision Mechanics, Duchnicka 3 Str., 01-796 Warsaw, Poland. DONATELLA GIURANNO is with the Foundry Research Institute and also with the CNR - Institute of Condensed Matter Chemistry and Technologies for Energy, Via De Marini, 6, 16149 Genova, Italy. AMANDA GENEROSI, BARBARA PACI, and DANIELE M. TRUCCHI are with the CNR - Institute of Structure of Matter, Via del Fosso del Cavaliere, 100, 00133 Roma, Italy.

Manuscript submitted July 12, 2018.

Article published online November 27, 2018 consumption. Among various available methods, latent heat thermal energy storage (LHTES) appears to be the attractive choice, mainly in terms of its large energy storage capacity. ${ }^{[1-3]}$ In this method, the heat absorbed or released during a phase transformation (namely latent heat or heat of fusion) is utilized to store the energy inside containers filled with a phase change material (PCM), and then is converted into electricity. Recently, silicon has been identified as promising PCM candidate for ultra-high temperature energy storage. Indeed, Si possesses very high heat of fusion $(1230 \mathrm{kWh} /$ $\mathrm{m}^{3}$ ), at least one order of magnitude higher than the currently used salts (e.g., $\left.\mathrm{NaNO}_{3}-110 \mathrm{kWh} / \mathrm{m}^{3}\right) .{ }^{[4]}$ For this reason, the use of $\mathrm{Si}$ as a PCM should significantly increase the energy density of LHTES devices. Nevertheless, in order to ensure a high reliability of Si-based LHTES devices, appropriate refractories for the PCM container operating at temperatures higher than the melting point of $\mathrm{Si}$, need to be identified. In order to suppress degradation of the involved materials during the long-term service, one of the key requirements to select the refractory is the inertness towards the contacting PCM, i.e., reflected by a low reactivity and non-wettability by molten Si. Moreover, a reasonably high mechanical strength of the selected refractory 


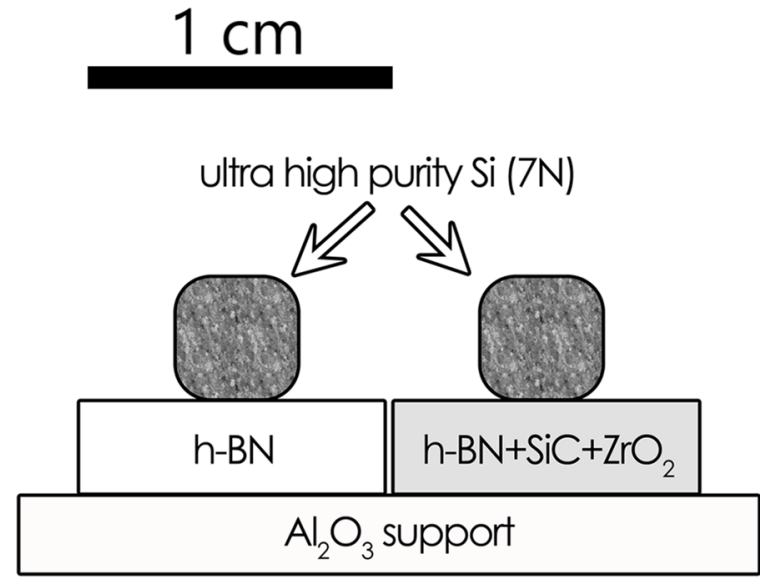

(a)

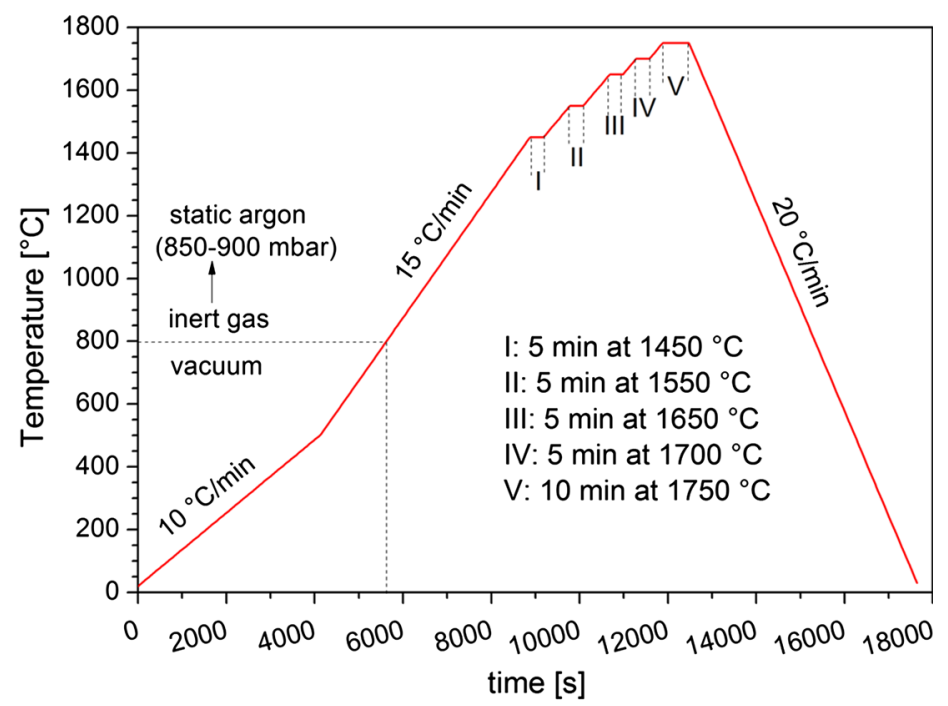

(b)

Fig. 1-Scheme of the two $\mathrm{Si}$ /substrate couples during wettability testing by using the " 2 in 1 " mode (a). Applied temperature profile for the heating/cooling cycle including five holding temperature intervals (i.e., $1450{ }^{\circ} \mathrm{C} / 5 \mathrm{~min} ; 1550{ }^{\circ} \mathrm{C} / 5 \mathrm{~min} ; 1650{ }^{\circ} \mathrm{C} / 5 \mathrm{~min} ; 1700{ }^{\circ} \mathrm{C} / 5 \mathrm{~min}$; and $\left.1750{ }^{\circ} \mathrm{C} / 10 \mathrm{~min}\right)$.

material is crucial to provide a longer durability of the PCM container operating under thermocycling conditions. However, due to a high chemical affinity of Si to oxygen, nitrogen, and carbon, almost all the commonly used refractories are well wetted by molten $\mathrm{Si}^{[5]}$ Among ceramic materials, hexagonal boron nitride $(\mathrm{h}-\mathrm{BN})$ is the only one reported exception exhibiting non-wetting behavior by $\mathrm{Si}$ at temperatures up to $1500{ }^{\circ} \mathrm{C} .{ }^{[6]}$

In our previous work, ${ }^{[7]}$ we have examined the wettability and reactivity at the $\mathrm{Si} / \mathrm{h}-\mathrm{BN}$ interface up to $1750{ }^{\circ} \mathrm{C}$. The results of sessile drop experiments evidenced that the non-wetting behavior (reflected by the contact angle $\theta>90 \mathrm{deg}$ ) is maintained up to $1650{ }^{\circ} \mathrm{C}$, while for higher temperatures the contact angle was near or slightly below 90 deg, corresponding to the non-wetting-to-wetting transition. The results of microstructural characterization revealed dissolution/ reprecipitation phenomena at the interface as the main interaction mechanism, without the formation of interfacial reactive products between liquid $\mathrm{Si}$ and $\mathrm{h}-\mathrm{BN}$. These findings provide a preliminary (since the thermal cycling behavior needs to be further examined) positive recommendation for the h-BN as the container material operating at temperatures up to $1650{ }^{\circ} \mathrm{C}$. On the contrary, to enhance its reliability the relatively low mechanical strength of this material needs to be improved. A common way to improve mechanical performance of ceramic materials is to reinforce them with other materials, i.e., to fabricate ceramic based composites ${ }^{[8]}$ Actually, various h-BN matrix composites are under development, ${ }^{[9]}$ while some of them have been already fully commercialized and are easily available in the form of customizable products (e.g., crucibles, nozzles, plates, tubes etc.) (e.g., Reference 10). Among various examining reinforcements, the most common are $\mathrm{ZrO}_{2}$ and $\mathrm{SiC}$ that are added to improve compressive strength, fracture toughness, thermal shock resistance, and oxidation resistance of the h-BN body. ${ }^{[1-13]}$

Despite a strong interest in industrial applications of h-BN-based composites, no one to the best of our knowledge has previously investigated their behavior in contact with molten $\mathrm{Si}$ at ultra-high temperatures. Therefore, the main purpose of the present work is to experimentally evaluate at temperatures up to $1750{ }^{\circ} \mathrm{C}$ the wettability and reactivity at the $\mathrm{Si} /(\mathrm{h}-\mathrm{BN}+\mathrm{SiC}+$ $\mathrm{ZrO}_{2}$ ) interface by using the sessile drop method.

\section{MATERIALS AND METHODS}

High purity $\mathrm{Si}$ and commercial sintered h-BN composite having the nominal phase composition of (h-BN $+\mathrm{SiC}+\mathrm{ZrO}_{2}$ ) were used for the sessile drop wetting test. As in our previous work, ${ }^{[7]}$ the selected Si material was amorphous polysilicon from the commercial Siemens process, with a purity of $7 \mathrm{~N}^{[14]}$ The commercially available (h- $\mathrm{BN}+\mathrm{SiC}+\mathrm{ZrO}_{2}$ ) hot isostatically pressed composite HeBoSint ${ }^{\circledR}$ O120 (Henze, Germany), was used as substrate. The applied sample preparation and testing procedures are detailed elsewhere. ${ }^{[7]}$ The Si/h-BN composite couple was subjected to the wettability test by the sessile drop method combined with a contact heating procedure, by using the experimental apparatus described in detail elsewhere. ${ }^{[15]}$ For the sake of comparison, the test was performed in "2 in 1" mode as shown in Figure 1(a) (i.e., two couples were simultaneously examined under the same experimental environment), by using as the counterpart the "pure" h-BN (HeBoSint ${ }^{\circledR}$ D100 material produced by Henze, Germany) examined in our previous work $\left.{ }^{[7]}\right)$. The applied testing procedure of the 

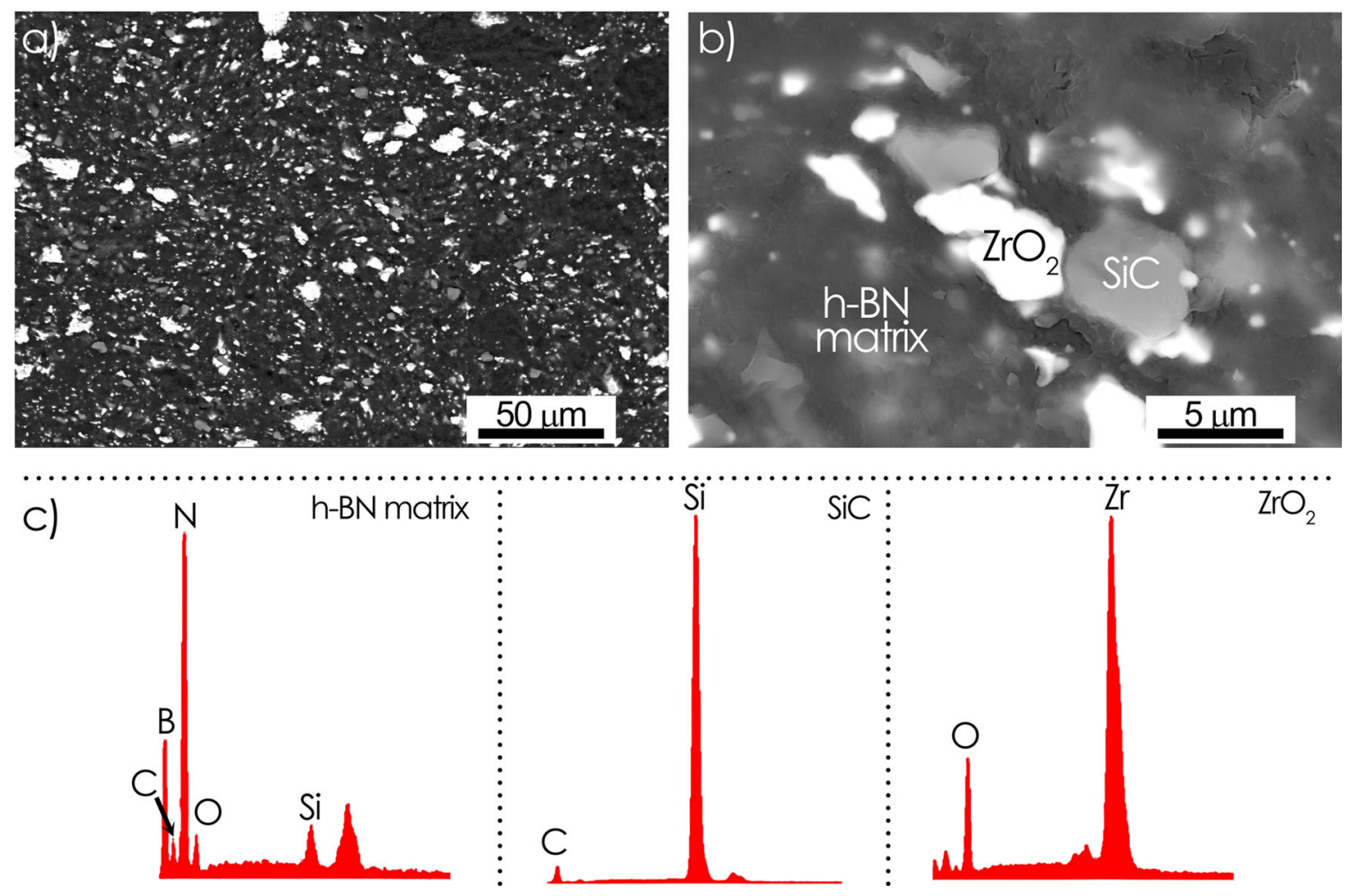

$\mathrm{ZrO}_{2}$

Fig. 2-SEM/EDS analyses of the (h-BN $\left.+\mathrm{SiC}+\mathrm{ZrO}_{2}\right)$ composite as-received: the SEM-BSE images at different magnifications $(a, b)$; most representative EDS spectra collected from various sites of the composite $(c)$.

heating/cooling scheme including five intervals (i.e., $1450{ }^{\circ} \mathrm{C} / 5 \mathrm{~min} ; \quad 1550{ }^{\circ} \mathrm{C} / 5 \mathrm{~min} ; \quad 1650^{\circ} \mathrm{C} / 5 \mathrm{~min}$; $1700{ }^{\circ} \mathrm{C} / 5 \mathrm{~min}$ and $\left.1750^{\circ} \mathrm{C} / 10 \mathrm{~min}\right)$ is shown in Figure 1(b). The wettability test was performed by heating the couples in two stages: from room temperature up to $T=800{ }^{\circ} \mathrm{C}$ under a high vacuum ( $p=1 \times 10^{-6} \mathrm{mbar}$ ); and from $T=800^{\circ} \mathrm{C}$ up to the testing temperature under a total pressure of $p=850$ to 900 mbar of inert gas (argon) with the aim to suppress the evaporation of silicon. The experiment was recorded with a rate of $100 \mathrm{fps}$ by using MC1310 high-speed camera. The acquired images were processed to calculate the contact angle $\theta$ by using a dedicated software (ASTRA2), as well as for preparing a fast-forward movie from a high-temperature test (Supplementary material).

After the wetting test, the solidified couples were removed from the chamber and their microstructural characterization was performed by using the Carl Zeiss Axio Observer ZM10 light microscope (LM) and FEI $\mathrm{Scios}^{\mathrm{TM}}$ field emission gun scanning electron microscope (FEG SEM) coupled with Energy Dispersive X-ray Spectroscopy (EDS). The examinations were performed both on top-views and cross-sectioned samples. The presence of particular phases in the h-BN composite in the as-received condition and after the high temperature test was analyzed by using PANanalytical Empyrean $\mathrm{X}$-ray diffractometer (XRD). In particular, the following parameters were applied upon acquiring XRD spectra: $\mathrm{Cu} \mathrm{K} \mathrm{K}_{\alpha}$ radiation (1.54060 А); generator settings:
$40 \mathrm{~mA}, 40 \mathrm{kV} ; 2 \theta$ range of 10 to $110 \mathrm{deg}$; a step size of $0.0020 \mathrm{deg}$.

\section{RESULTS}

\section{A. Characterization of h-BN Composite in the As-received Condition}

In Figure 2, the results of SEM/EDS analyses of the h-BN composite in the as-received condition are shown. Both $\mathrm{SiC}$ and $\mathrm{ZrO}_{2}$ particles (gray and white on SEM BSE images, respectively) embedded in the h-BN matrix have irregular shape and size up to $10 \mu \mathrm{m}$ (Figures 2(a) and (b)). The total volumetric fraction of $\mathrm{SiC}$ and $\mathrm{ZrO}_{2}$ particles was estimated as $15.1 \pm 0.8$ pct by stereological analyses of SEM images. In addition, it should be noted that due to a large fraction of very fine (submicron size) reinforcing particles, the peaks coming from $\mathrm{Si}, \mathrm{C}$, $\mathrm{Zr}$, and $\mathrm{O}$ were also detected on EDS spectra taken from the h-BN matrix (Figure 2(c)).

The results of SEM/EDS inspections were confirmed by XRD phase analyses. As it was expected, three distinct phases are detected on the XRD spectrum (Figure 3) and assigned, respectively, to h-BN (full squaresICDD:96-900-8998), cubic SiC (full circles-Moissanite 3C-ICDD:96-101-1032), and monoclinic $\mathrm{ZrO}_{2}$ (unmarked peaks — baddeleyite ICDD:96-101-0913).

However, as suggested in the literature ${ }^{[16]}$ the addition of $\mathrm{ZrO}_{2}$ to the h-BN composite may result in the 


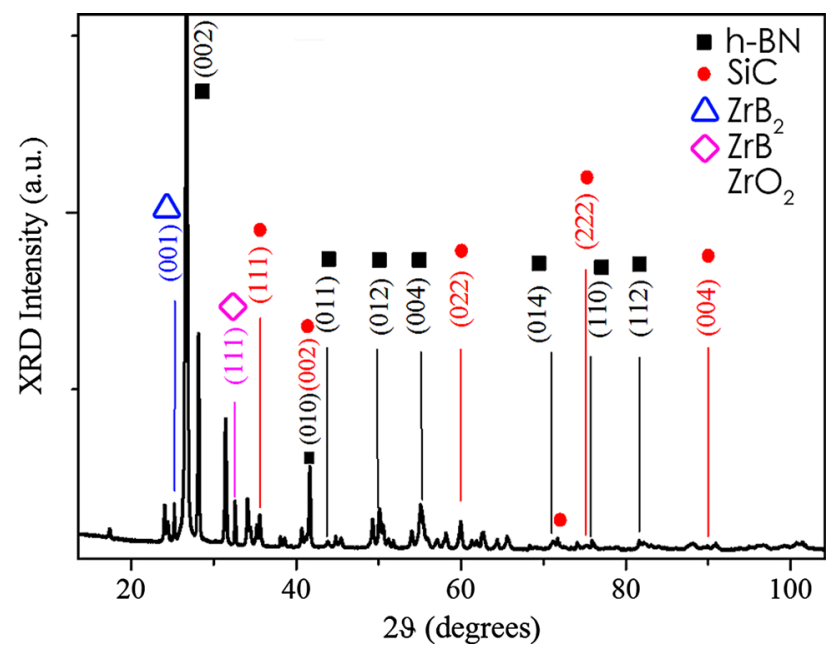

Fig. 3-XRD spectrum of $\mathrm{h}-\mathrm{BN}+\mathrm{SiC}+\mathrm{ZrO}_{2} \quad$ composite as-received.

formation of zirconium borides during sintering. The presence of both $\mathrm{ZrB}$ (rhombus, ICDD:96-900-8777, Crystal system: Cubic, Space group: Fm-3m, Space group number: 225) and $\mathrm{ZrB}_{2}$ (triangles) were confirmed in the as-received material. The coexistence of two zirconium borides might be explained by a partial evaporation of $\mathrm{B}$ from the $\mathrm{ZrB}_{2} \cdot{ }^{[16]}$ Moreover, the high sharpness of the peaks indicates well-crystallized phases.

\section{B. Wetting and Spreading Behavior}

A fast-forward video of the wettability test is added as Supplementary Material 1. The applied " 2 in 1" procedure allows for a real-time comparison of the pure h-BN (on the left) and the h-BN composite (on the right) substrates upon testing in contact heating with pure $\mathrm{Si}$ up to $1750{ }^{\circ} \mathrm{C}$. First of all, it should be noted that the $\mathrm{Si} /$ (h-BN $+\mathrm{SiC}+\mathrm{ZrO}_{2}$ ) composite couple exhibited more stable behavior than the $\mathrm{Si} / \mathrm{h}-\mathrm{BN}$ counterpart. In contrast to the pure h-BN sample, weak $\mathrm{Si}$ drop vibrations were observed on the composite substrate only for few seconds after the melting of $\mathrm{Si}$. As we have concluded in our previous work, ${ }^{[7]}$ the drop vibration effect originates from the substrate dissolution followed by a releasing of overbalanced nitrogen through gas/ liquid and gas/solid interfaces. Thus, it seems that highly heterogeneous structure of the composite substrate composed of h-BN matrix and at least four phases (primary $\mathrm{SiC}$ and $\mathrm{ZrO}_{2}$ as well as secondary $\mathrm{ZrB}$ and $\mathrm{ZrB}_{2}$ ) somehow suppresses this phenomenon. This statement is also confirmed by a more undetectable dewetting phenomenon during the cooling of $\mathrm{Si} /\left(\mathrm{h}-\mathrm{BN}+\mathrm{SiC}+\mathrm{ZrO}_{2}\right)$ couple.

In Figure 4, the wetting kinetics is shown. For the $\mathrm{Si} /$ (h-BN $+\mathrm{SiC}+\mathrm{ZrO}_{2}$ ) couple, the increase of the testing temperature up to $1750{ }^{\circ} \mathrm{C}$ results in a monotonic decrease of the contact angle from $\theta_{1420}=133 \pm 1 \mathrm{deg}$ to $\theta_{1750}=113 \pm 1 \mathrm{deg}$. The observed $\theta$ vs $t$ behavior characterized by a slower spreading time is the main feature of the reactive wetting, i.e., the interaction dominated either by a dissolution of the substrate

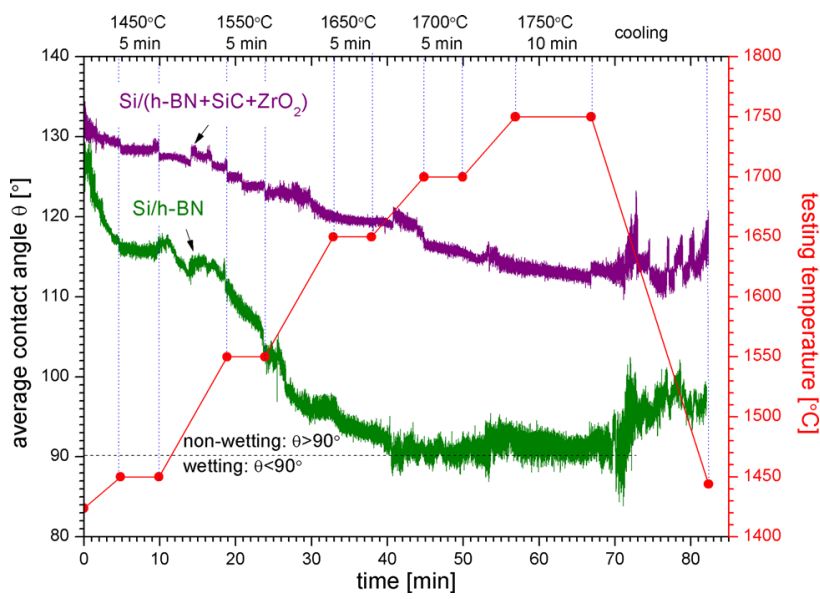

Fig. 4-Wetting kinetics of the $\mathrm{Si} /\left(\mathrm{h}-\mathrm{BN}+\mathrm{SiC}+\mathrm{ZrO}_{2}\right)$ and $\mathrm{Si} /$ h-BN ${ }^{[7]}$ couples tested at temperatures up to $1750^{\circ} \mathrm{C}$.

followed by reprecipitation during cooling or by the formation of new interfacial compounds. ${ }^{[17]}$ Contrarily, the behavior of $\mathrm{Si} /$ pure h-BN couple showed a sharp decrease of $\theta$ value down to $\theta_{1650}=117 \pm 5 \mathrm{deg}$ just after the melting of $\mathrm{Si}$, followed by a further decreasing to $\theta_{1650}=90 \pm 5 \mathrm{deg}$ (i.e., transition from non-wetting to wetting). Since all phases involved in the composite substrate are wettable by $\mathrm{Si}$ at such high temperature (for $\mathrm{SiC}, \mathrm{ZrO}_{2}$, and $\mathrm{ZrB}_{2}$ the corresponding contact angle values are $\theta_{1480} \sim 40 \mathrm{deg},{ }^{[18]} \theta_{1420} \sim 80 \mathrm{deg},{ }^{[5]}$ and $\theta_{1420} \sim 45 \mathrm{deg},{ }^{[19]}$ respectively), the contact angles values observed at $\mathrm{Si} /\left(\mathrm{h}-\mathrm{BN}+\mathrm{SiC}+\mathrm{ZrO}_{2}\right)$ interface are quite surprising. Nevertheless, as discussed in Section III-C- 1 , the outcomes from microstructural examinations performed on the solidified sessile drop couples after the wetting tests might be helpful to identify the possible reasons for such behavior.

\section{Reactivity in the $\mathrm{Si} /\left(\mathrm{h}-\mathrm{BN}+\mathrm{SiC}+\mathrm{ZrO}_{2}\right)$ System at Temperatures up to $1750{ }^{\circ} \mathrm{C}$-Structural Characterization}

1. Examinations of the $\left(h-B N+S i C+\mathrm{ZrO}_{2}\right)$ composite substrate

The macroscopic view of the $\mathrm{Si} /\left(\mathrm{h}-\mathrm{BN}+\mathrm{SiC}+\mathrm{ZrO}_{2}\right)$ couple before and after the wettability test is presented in Figure 5. The inspection revealed a slight color changeover of the substrate and the formation of a dark ring around the solidified drop. It has been reported by Eichler and Lesniak ${ }^{[20]}$ that such change in optical appearance of pure h-BN substrate subjected to heat treatments at ultra-high temperatures (up to $1800{ }^{\circ} \mathrm{C}$ ) is related to a thermal degradation of h-BN crystal lattice assisted by the formation of nitrogen vacancies. However, in the present case of the (h-BN + $\mathrm{SiC}+\mathrm{ZrO}_{2}$ ) composite, the effect of reactions and phase transformations taking place in the substrate volume during the high temperature exposure should be also considered.

More detailed structural examinations of the substrate were carried out by using the SEM/EDS technique. The top view observations revealed that the dark 
ring on the $\left(\mathrm{h}-\mathrm{BN}+\mathrm{SiC}+\mathrm{ZrO}_{2}\right)$ substrate around the drop was formed probably due to $\mathrm{Si}$ evaporation, as it is documented by a gradual change of its content with increasing distance from the triple line (Figure 6(a)). Moreover, the presence of numerous fine droplets and few agglomerates filling cavities in the h-BN composite substrate, was also detected (Figure 6(b)). The results of local EDS analyses revealed an increase of $\mathrm{Zr}$ and $\mathrm{B}$ content in these particles suggesting a possible formation of zirconium borides.

In Figure 7, a macroscopic image and low-magnification light microscopy images of the cross-sectioned (h-BN $+\mathrm{SiC}+\mathrm{ZrO}_{2}$ ) substrate after the wettability test are shown. It is clearly evident that the ultra-high testing temperature resulted in a strikingly inhomogeneous structure of the composite as shown in Figure 7(a), where porous reacted zone (I), more dense transition

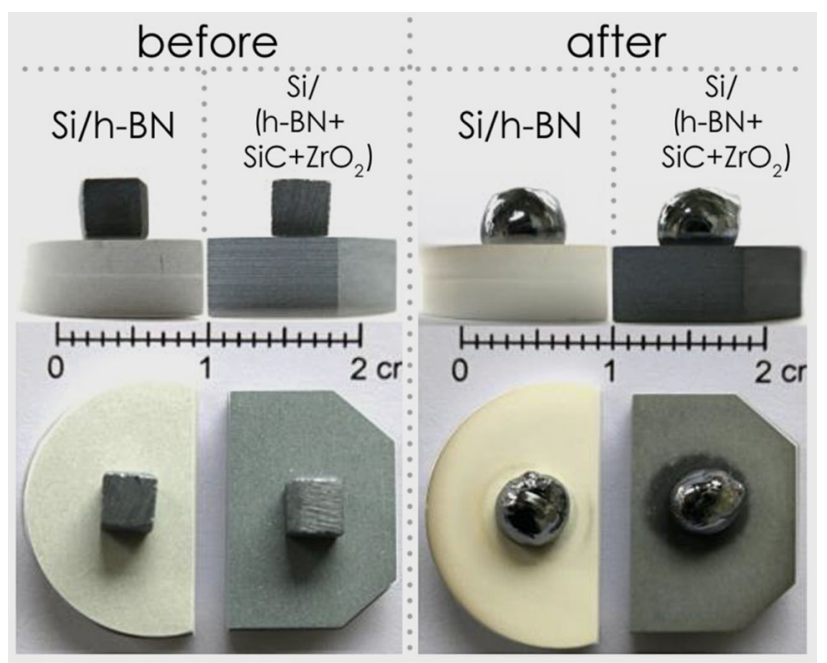

(a)

(b)

Fig. 5-Macroscopic top-view images of the $\mathrm{Si} / \mathrm{h}$-BN couples before (a) and after $(b)$ the high temperature test at temperatures up to $1750{ }^{\circ} \mathrm{C}$ (the scale is in centimeters).
(II), and unreacted zones (III) are well distinguished (Figures 7(b) and (c)).

Under higher microscopic magnifications, it is found that the outer part of the reacted zone (Figures 8(a) and (b)) contains mainly a large number of variously sized pores (with a diameter up to $\sim 50 \mu \mathrm{m}$ ) and $\mathrm{Zr}-\mathrm{B}$ particles that were also visible in top-view observations. Accordingly, it should be noted that the porous layer was completely free of $\mathrm{SiC}$ particles that in turn were presented in the transition and unreacted zones (Figures 7(c) and 8(b)).

Each zone was also analyzed by the SEM/EDS technique (Figures 9 and 10). The obtained results point towards the following phase composition of each zone:

(I) the existence of only zirconium boride phases and a lack of primary $\mathrm{SiC}$ and $\mathrm{ZrO}_{2}$ in the porous zone (Figures 9(b) and 10(a));

(II) a mixture nature of the transition zone characterized by the coexistence of zirconium borides, $\mathrm{ZrO}_{2}$, and $\mathrm{SiC}$ phases (Figures 9(c) and 10(b)); (III) a not strongly altered structure of the unreacted zone as compared to the as-received material (see Figure 2), i.e., a presence of primary $\mathrm{ZrO}_{2}$ and $\mathrm{SiC}$ particles and a lack of secondary zirconium borides (Figures 9(d) and 10(c)).

The results of microscopic characterization are in a good agreement with XRD analyses. As it is shown in Figure 11, the phase composition and microstructure of the h-BN composite were strongly modified after the high-temperature experiment. The following findings were noted by comparing XRD spectra obtained from the as-received and high-temperature tested (h-BN + $\mathrm{SiC}+\mathrm{ZrO}_{2}$ ) composite samples:

1. diffraction lines from the $\mathrm{h}-\mathrm{BN}$ phase were unchanged (squares);

2. reflections from the $\mathrm{SiC}$-moissanite phase disappeared;

3. both $\mathrm{ZrB}$ (rhombus) and $\mathrm{ZrB}_{2}$ (triangles) lines were still present. The peaks from zirconium boride phases became stronger and several more reflections
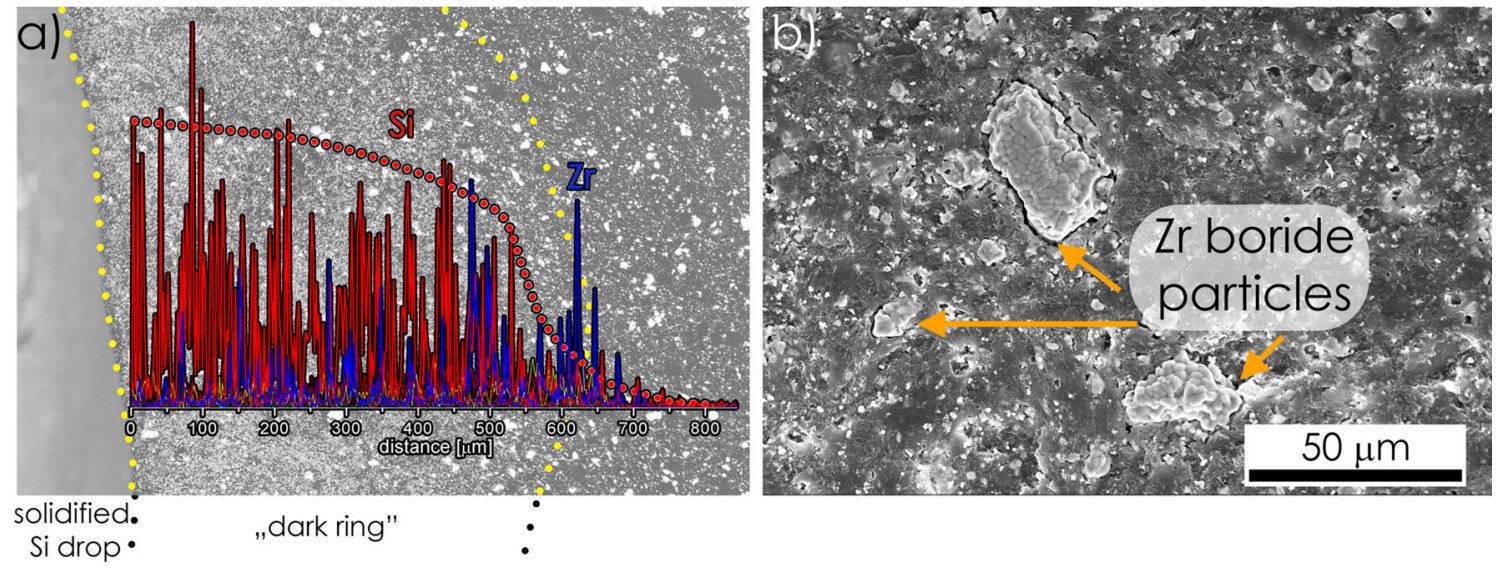

Fig. 6- $\mathrm{SEM} / \mathrm{EDS}$ top-view examinations of the $\mathrm{Si} /\left(\mathrm{h}-\mathrm{BN}+\mathrm{SiC}+\mathrm{ZrO}_{2}\right)$ couple after the high temperature wettability test. EDS line-scan of elements as a function of the distance from the drop $(a)$. Magnified SEM image of the dark ring area with fine $\mathrm{Zr}$ - and B-enriched particles $(b)$. 


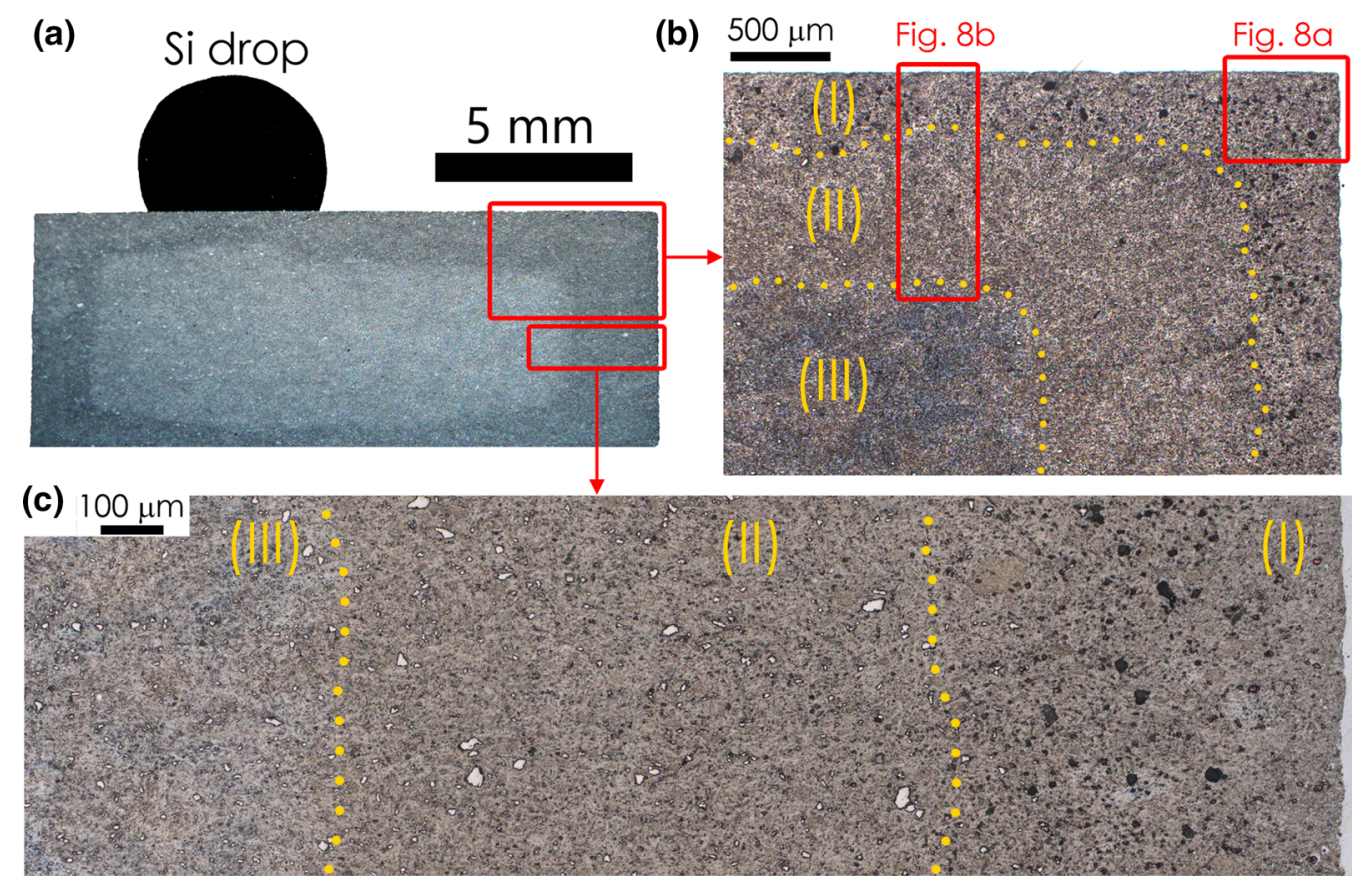

Fig. 7-Cross-sectioned $\mathrm{Si} /\left(\mathrm{h}-\mathrm{BN}+\mathrm{SiC}+\mathrm{ZrO}_{2}\right)$ couple after the high temperature wettability test at temperatures up to $1750{ }^{\circ} \mathrm{C}$. Macroscopic image $(a)$, light microscopy images $(b, c)$.

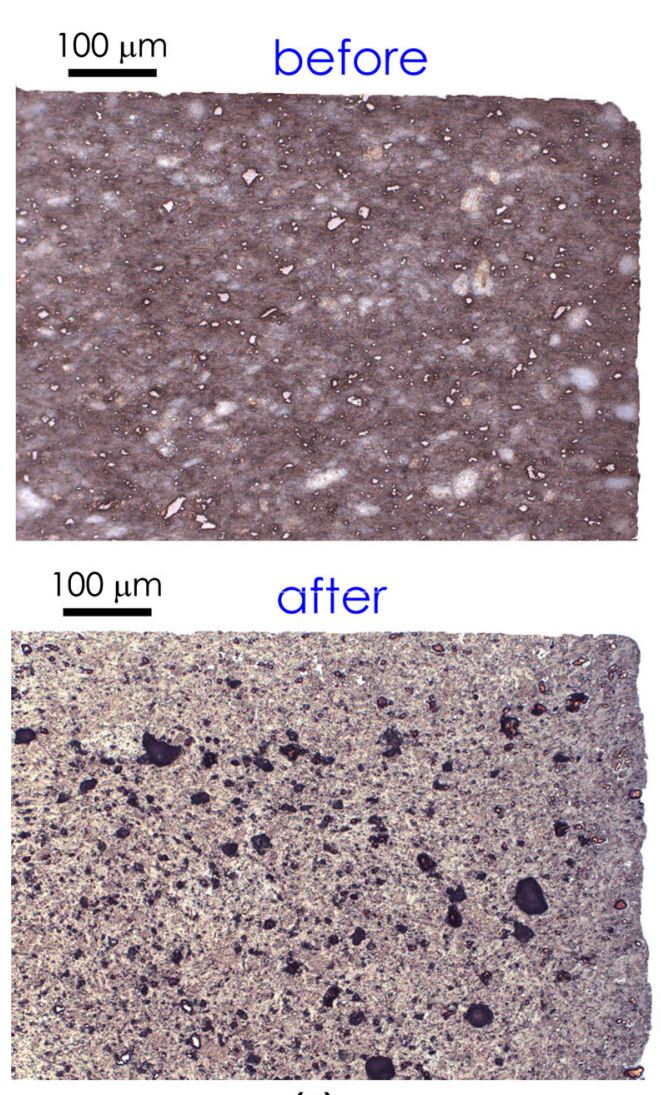

(a)

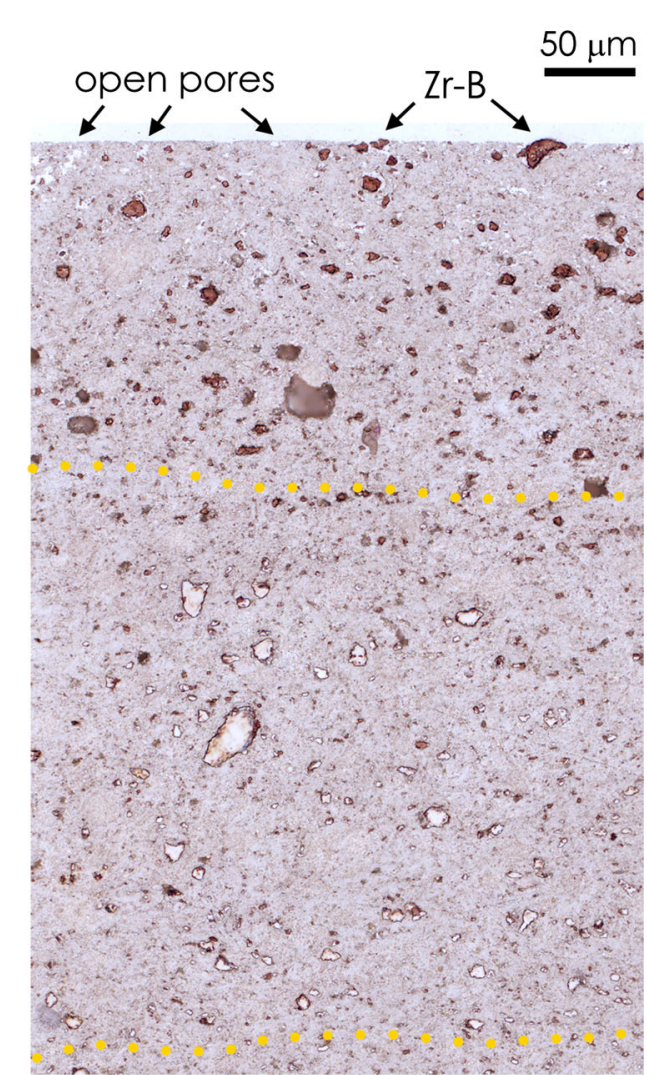

(b)

Fig. 8-A comparison of light microscopy (LM) images of cross-sectioned $\mathrm{Si} /\left(\mathrm{h}-\mathrm{BN}+\mathrm{SiC}+\mathrm{ZrO}_{2}\right)$ substrate taken before and after the wettability test at $\mathrm{T}$ up to $1750{ }^{\circ} \mathrm{C}(a)$. Magnified views of the porous reacted zone, transition part, and unreacted area $(b)$. 

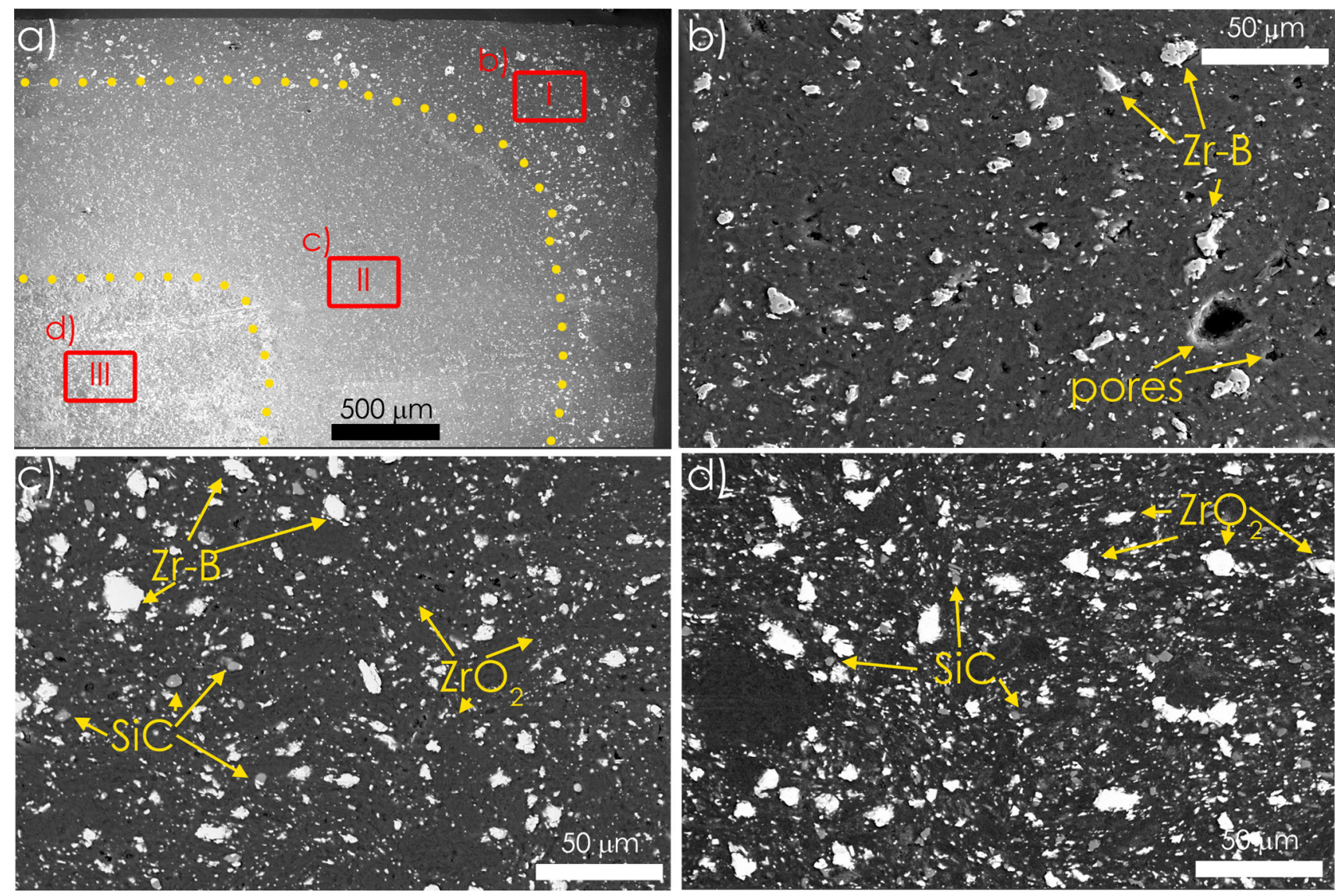

Fig. 9- $\mathrm{SEM}$ analyses of the cross-sectioned (h-BN $\left.+\mathrm{SiC}+\mathrm{ZrO}_{2}\right)$ substrate after the wettability test at $\mathrm{T}$ up to $1750{ }^{\circ} \mathrm{C}($ a). Magnified $\mathrm{SEM}$ images of the porous reacted zone $(b)$, transition part $(c)$, and unreacted area $(d)$. The particles in each zone were identified based on the results of SEM/EDS analyses shown in Fig. 10.

are visible, as compared to the material in the as-received condition ${ }^{[21,22]}$;

4. the monoclinic $\mathrm{ZrO}_{2}$ is no longer present. Literature predicts ${ }^{[16]}$ that at high temperatures (above $\left.1050{ }^{\circ} \mathrm{C}\right)$, a conversion into tetragonal $\mathrm{ZrO}_{2}$ might occur. However, the main peak of $t-\mathrm{ZrO}_{2}(100 \mathrm{deg}$ relative intensity) at approximately $2 \theta=30.0 \mathrm{deg}$ is missing, indicating that in the present case such conversion did not take place. Therefore, this fact suggests that the monoclinic zirconia presented in the as-received material was completely transformed to zirconium borides during the high-temperature exposure.

\section{Examinations of the Si drop and $\mathrm{Si}$}

$\left(h-B N+S i C+\mathrm{ZrO}_{2}\right)$ interface

The interface area of cross-sectioned solidified $\mathrm{Si} /$ (h-BN $+\mathrm{SiC}+\mathrm{ZrO}_{2}$ ) couple was examined by the SEM/EDS technique (Figure 12). First of all, a drastic change of chemistry of initially pure $\mathrm{Si}(7 \mathrm{~N})$ towards Si-B-X alloy was noticed. The presence of easily recognized $\left(\mathrm{Si}+\mathrm{SiB}_{3}\right)$ eutectic needle-like features surrounding $\mathrm{Si}$ crystals inside the solidified drop is revealed (Figure 12(a)). In addition, few fine particles enriched in $\mathrm{Al}, \mathrm{Ca}$, or $\mathrm{Fe}$ formed due to the presence of impurities coming from sintering aids were also observed (Figure 12(b)). Moreover, numerous SiC crystals were detected at the drop/substrate interface (Figures 12(a) and (c)). These interfacial SiC crystals were surrounded by large crystals of Si-solid solution (white color) decorated by Si-B eutectic (Figure 12(c)), simply confirming that $\mathrm{SiC}$ phase is formed as the first compound during cooling from $1750{ }^{\circ} \mathrm{C}$. As previously, the SEM and LM inspections of cross-sectioned substrate-side interface revealed almost complete lack of $\mathrm{SiC}$ particles as well as the presence of zirconium boride particles in a near vicinity of the interface (at a distance of $\sim 150 \mu \mathrm{m}$ ) (Figure 12(d)). The primary particles were in turn observed in the unreacted zone below the drop (Figure 12(e)).

\section{DISCUSSION}

The results of contact heating test of $\mathrm{Si} /(\mathrm{h}-\mathrm{BN}+$ $\mathrm{SiC}+\mathrm{ZrO}_{2}$ ) couple at temperatures up to $1750{ }^{\circ} \mathrm{C}$ revealed an occurrence of phase and structural transformations in the composite substrate affecting the observed wetting behavior. First of all, the existence of zirconium borides $\left(\mathrm{ZrB}_{2}\right.$ and $\left.\mathrm{ZrB}\right)$ was revealed both in 

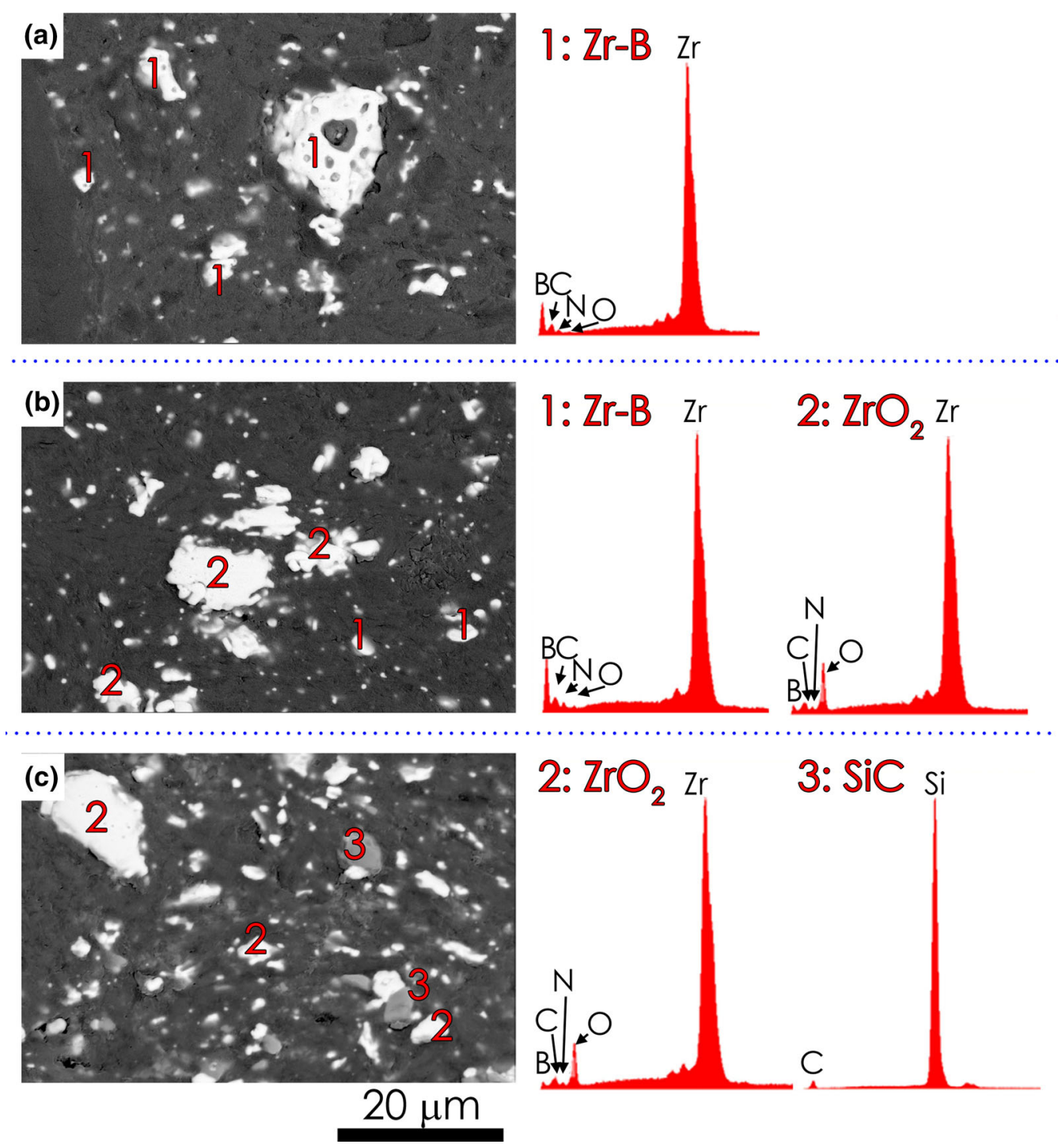

Fig. $10-\mathrm{SEM} / \mathrm{EDS}$ analyses of the cross-sectioned (h-BN $+\mathrm{SiC}+\mathrm{ZrO}_{2}$ ) substrate after the wettability test at $\mathrm{T}$ up to $1750{ }^{\circ} \mathrm{C}$. Magnified SEM images and corresponding EDS spectra of particles located inside of the porous reacted zone $(a)$, transition part $(b)$, and unreacted area $(c)$.

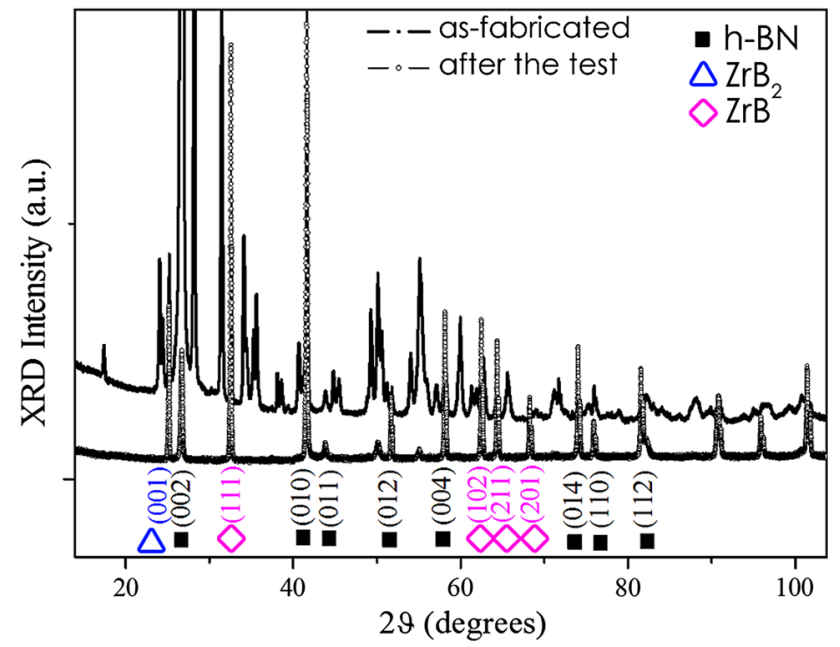

Fig. 11-Comparison of XRD spectra of the as-received and high-temperature tested h-BN $+\mathrm{SiC}+\mathrm{ZrO}_{2}$ composite samples. the as-received and high temperature tested composite samples. Thus, it seems that the mechanism of zirconium boride formation was starting during the sintering step, and then continued within the wetting experiment. Most probably, the following reaction of $\mathrm{ZrO}_{2}$ with $\mathrm{BN}$ and $\mathrm{C}$, assisted by $\mathrm{CO}$ and $\mathrm{N}_{2}$ gaseous products, was involved ${ }^{[23]}$ :

$$
\begin{gathered}
\mathrm{ZrO}_{2}+2 \mathrm{BN}+2 \mathrm{C} \rightarrow \mathrm{ZrB}_{2}+2 \mathrm{CO} \uparrow+\mathrm{N}_{2} \uparrow \\
\Delta G<0, T>1115^{\circ} \mathrm{C}
\end{gathered}
$$

It has been theoretically calculated by Yan et al. ${ }^{[23]}$ that Gibbs free energy $\Delta \mathrm{G}$ of the Reaction [1] becomes negative above $1115^{\circ} \mathrm{C}$; and after that the occurrence of this reaction at $\sim 1480{ }^{\circ} \mathrm{C}$ has been experimentally proven by the results of calorimetric and in situ X-ray diffraction studies of milled powders. What should be noted is that these authors also predicted that $\mathrm{ZrB}_{2}$ phase might be alternatively formed from the $\left(\mathrm{ZrO}_{2}+\right.$ 

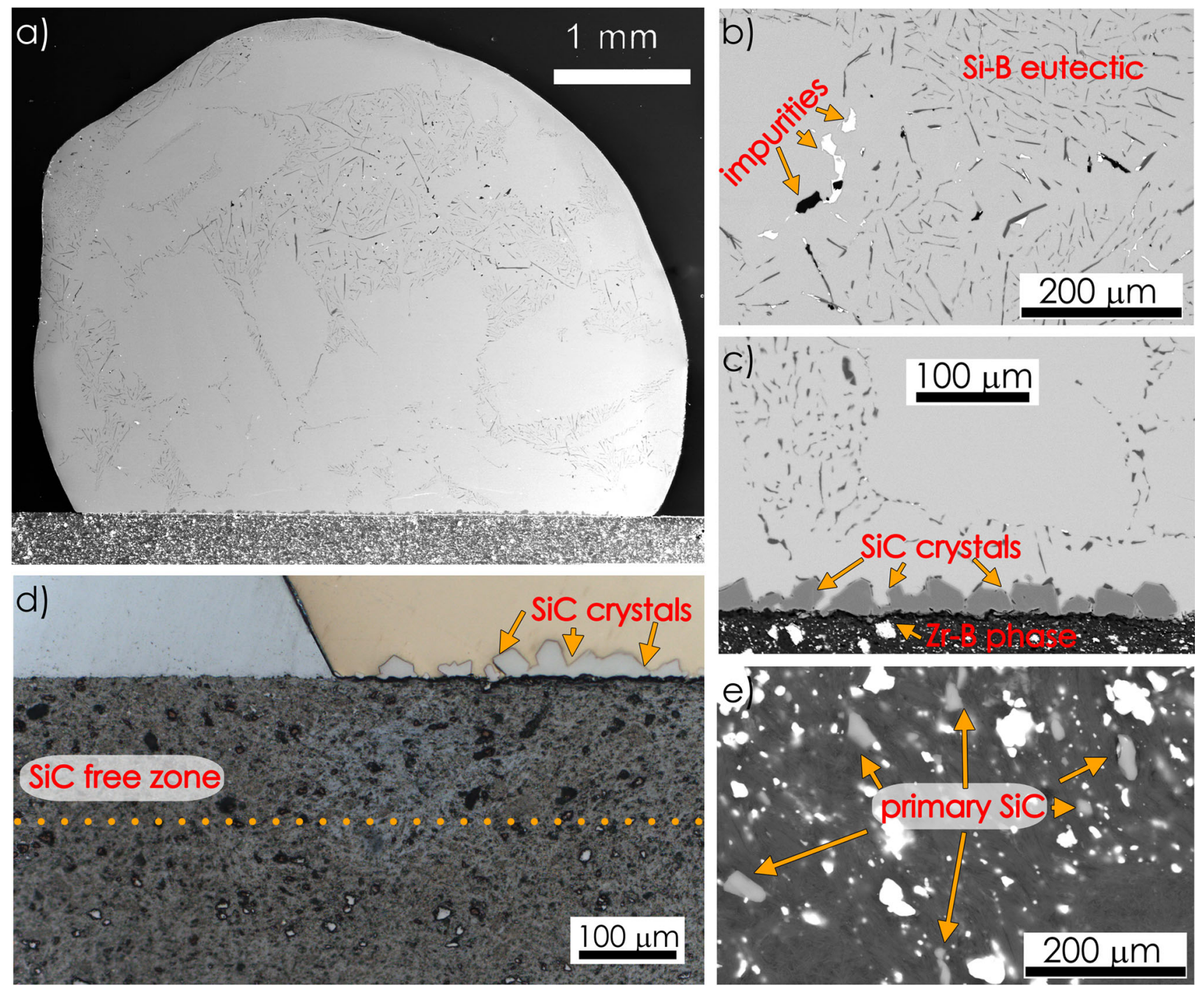

Fig. 12-SEM/EDS $(a-c, e)$ and $\mathrm{LM}(d)$ examinations of the cross-sectioned $\mathrm{Si} /\left(\mathrm{h}-\mathrm{BN}+\mathrm{SiC}+\mathrm{ZrO}_{2}\right)$ couple: (a) overall view; (b) Si-B eutectics and minor impurities; (c) discontinuous layer of SiC crystals at the interface; (d) LM image of the near surface substrate zone showing a lack of $\mathrm{SiC}$ particles; (e) substrate region at higher distance from the drop.

$\mathrm{C}+\mathrm{BN}$ ) precursor powders mixture via a two-step reaction including the formation of $\mathrm{ZrC}$ intermediate phase at lower temperature (Eq. [2a]), acting subsequently as the $\mathrm{BN}$ reducing reagent (Eq. [2b]).

$$
\mathrm{ZrO}_{2}+3 \mathrm{C} \rightarrow \mathrm{ZrC}+2 \mathrm{CO} \uparrow \quad \Delta G<0, T>1078^{\circ} \mathrm{C}
$$

$\mathrm{ZrC}+2 \mathrm{BN} \rightarrow \mathrm{ZrB}_{2}+\mathrm{N}_{2} \uparrow+\mathrm{C} \quad \Delta G<0, T>1287^{\circ} \mathrm{C}$

Nevertheless, as it comes from the Reaction [1] and Reactions [2a, 2b], the transformation of $\mathrm{ZrO}_{2}$ into zirconium borides requires a pre-existence of free $\mathrm{C}$ in the system. Kumar et al. ${ }^{[24,25]}$ have documented that one of the main features of the non-wetting interaction of (h-BN $+\mathrm{SiC}+\mathrm{ZrO}_{2}$ ) composite with molten Si-killed steel at temperatures up to $1600{ }^{\circ} \mathrm{C}$ is a thermal decomposition followed by a dissolution and/or removal of $\mathrm{SiC}$, accompanied by formation of gaseous $\mathrm{CO}$ product, and thus leading to an existence of a porous zone in the affected volume of the composite. Analogously, since it is well established that $\mathrm{SiC}$ is also completely unstable in contact with molten $\mathrm{Si}^{[5]}$ we may assume a similar high temperature structural evolution mechanism for the $\mathrm{Si} /\left(\mathrm{h}-\mathrm{BN}+\mathrm{SiC}+\mathrm{ZrO}_{2}\right)$ system involving the decomposition process of $\mathrm{SiC}$ phase and giving free carbon needed for the Reactions [1] and/or [2a, 2b].

Furthermore, it is reasonable to assume that the composite also contained some amount of boron oxide $\left(\mathrm{B}_{2} \mathrm{O}_{3}\right)$. It is commonly introduced either as a sintering aid for rapid densification, or due to the oxidation of $\mathrm{BN}$ powder during sintering step.

The $\mathrm{B}_{2} \mathrm{O}_{3}$ melts at relatively low temperature $\left(T=452{ }^{\circ} \mathrm{C}\right)$ and then easily evaporates under high vacuum conditions. ${ }^{[26]}$ The presence of liquid $\mathrm{B}_{2} \mathrm{O}_{3}$ also 
facilitates the process of $\mathrm{SiC}$ dissolution/decomposition in accordance to the following reaction ${ }^{[27]}$ :

$$
\mathrm{SiC}+\mathrm{B}_{2} \mathrm{O}_{3(l)} \rightarrow \mathrm{Si}+\mathrm{B}_{2} \mathrm{O}_{2} \uparrow+\mathrm{CO} \uparrow
$$

Furthermore, as it was discussed by Chen et al. ${ }^{[28]}$ the impurity $\mathrm{B}_{2} \mathrm{O}_{3}$ contained in $\mathrm{BN}$ facilitates the formation of $\mathrm{ZrB}$ phases in nominal (h-BN $+\mathrm{SiC}+\mathrm{ZrO}_{2}$ ) material through the reactions with zirconia and silicon carbide also assisted by formed gases.

Therefore, reactions between composite constituents assisted by formed gaseous reaction products; as well as existence of phases (e.g., liquid $\mathrm{B}_{2} \mathrm{O}_{3}$ ) that evaporate rapidly under low-oxygen partial-pressure atmosphere, might be indicated as a possible explanation for the observed inhomogeneity of the composite (especially by the presence of a near-surface porous zone).

A high probability for the occurrence of this mechanism during the high temperature test is also justified by the following evidences observed in the outer part of the tested substrate: (I) a lack of $\mathrm{SiC}$ particles and (II) a coexistence of zirconium borides and pores (Figures 8(b) and 9(b)). Accordingly, it is suggested that the porosity might be formed in accordance to aforementioned reactions including (I) the $\mathrm{SiC}$ decomposition (that can be alternatively assisted by the production of $\mathrm{B}_{2} \mathrm{O}_{2}$ gas-Reaction [3]) and (II) the transformation of $\mathrm{ZrO}_{2}$ accompanied by of the production of gaseous $\mathrm{CO}$ and $\mathrm{N}_{2}$, respectively.

Furthermore, the in situ formation of porosity (and especially open pores) in the outer part of the composite alters its initial surface morphology, and thus might also affect the wetting behavior and contact angle values recorded during the wetting test with molten $\mathrm{Si}$. As we previously stated, ${ }^{[7]}$ the vibration of Si drop on the h-BN ceramic at high temperature is caused by the action of gaseous nitrogen formed by dissolution of the substrate and then is released through gas/liquid interface. In the present case, it seems that the absence of $\mathrm{Si}$ drop vibration on the (h- $\left.\mathrm{BN}+\mathrm{SiC}+\mathrm{ZrO}_{2}\right)$ composite substrate could be justified by the existence of open porosity in the near surface area, enabling a fast gas removing $\left(\mathrm{N}_{2}, \mathrm{CO}\right)$ from the interaction zone. This situation is very similar to that reported by Kanai et al. ${ }^{[29]}$ for the $\mathrm{Si} /$ $\mathrm{SiO}_{2}$ system. They documented that the presence of grooves or dimples on the $\mathrm{SiO}_{2}$ substrates facilitates the "leakage" of $\mathrm{SiO}$ gaseous product; and as a result, the $\mathrm{Si}$ droplet did not vibrate, as opposite to the counterpart tested on the silica substrate having flat surfaces. Consequently, since conditions for perfectly flat and smooth surface are not fulfilled in such case, the measured contact angle values, probably overestimated in some extent, should be treated as apparent.

However, based on the obtained wetting kinetics curve (Figure 4) corresponding to an occurrence of either dissolution of solid substrate followed by a reprecipitation or the formation of new interfacial compounds, ${ }^{[17]}$ the interaction mechanism in the $\mathrm{Si} /$ (h-BN $+\mathrm{SiC}+\mathrm{ZrO}_{2}$ ) system at temperatures up to $1750{ }^{\circ} \mathrm{C}$ might be described as follows:
1. The h-BN matrix is slightly dissolved in the molten $\mathrm{Si}$, while the dissolution rate and degree increase with rising temperature.

2. The substrate dissolution process is assisted by a diffusion of boron, nitrogen and trace impurities leading to a gradual change of chemistry of molten Si towards Si-B-X alloys.

3. SiC particles embedded in the near surface area of h-BN matrix are decomposed in contact with molten $\mathrm{Si}$ (according to $\mathrm{Si}+\mathrm{SiC} \rightarrow \mathrm{Si}+\mathrm{C}$ mechanism) while reactively formed $\mathrm{C}$ is dissolved in liquid $\mathrm{Si}$ and then rebuilt during cooling in a form of $\mathrm{SiC}$ particles at the interface on the drop side (dissolution-reprecipitation mechanism),

4. $\mathrm{ZrO}_{2}$ is unstable at such high testing temperatures, and under the presence of free $\mathrm{C}$, it is transformed to more stable zirconium borides in accordance to reactions (1) or (2).

\section{SUMMARY AND CONCLUSIONS}

In this work, the high temperature interaction of commercially available $\left(\mathrm{h}-\mathrm{BN}+\mathrm{SiC}+\mathrm{ZrO}_{2}\right)$ composite with molten $\mathrm{Si}$ was experimentally examined by sessile drop experiments carried out at temperatures up to $1750{ }^{\circ} \mathrm{C}$. The obtained results show that the examined h-BN composite exhibits a lack of wettability with molten $\mathrm{Si}$ over the whole examined temperature range. The recorded contact angle of $\theta_{1420}=133 \pm 1$ to $\theta_{1750}=113 \pm 1 \mathrm{deg}$ is distinctly higher than those measured for the $\mathrm{Si} /$ pure h-BN system under the same operating conditions $\left(\theta_{1420}=129 \pm 1 \quad\right.$ to $\theta_{1750}=90 \pm 5 \mathrm{deg}$, respectively). Based on the results of LM, SEM/EDS and XRD analyses, it is proposed that the involved ultra-high temperature interaction mechanism in the $\mathrm{Si} /\left(\mathrm{h}-\mathrm{BN}+\mathrm{SiC}+\mathrm{ZrO}_{2}\right)$ system is mostly dominated by two phenomena: (i) a dissolution of the h-BN substrate leading to a change of chemistry of molten Si toward a Si-B- $X$ alloy and (ii) a formation of discontinuous interfacial $\mathrm{SiC}$ layer during the cooling step.

In the view of non-wettable surface requirement, it is reasonable to conclude that the investigated $(\mathrm{h}-\mathrm{BN}+$ $\mathrm{SiC}+\mathrm{ZrO}_{2}$ ) composite as container material for molten PCM will allow for increasing the operating temperature of the LHTES system, in respect to the pure h-BN.

On the other hand, the results of structural examinations point towards a lack of thermodynamic equilibrium in the as-received material under applied testing conditions. An occurrence of chemical reactions between composite components leading to significant changes of its microstructure and phase composition due to the ultra-high temperature exposure was observed.

The structural evolution of the examined h-BN-based composite is dominated by the thermal destabilization of primary $\mathrm{SiC}$ phase upon high temperature exposition favoring reactions between the other composite components (h-BN and $\mathrm{ZrO}_{2}$ ). Consequently, the structure becomes strongly inhomogeneous with easily 
distinguished reacted and unreacted zones separated by the transition area. The reacted zone is characterized by transformation of zirconia to zirconium borides. Moreover, the reaction is accompanied by gaseous products leading to the formation of porosity in the outer zone of the composite substrate.

A thermal cycling behavior of the $\mathrm{Si} /(\mathrm{h}-\mathrm{BN}+\mathrm{SiC}+$ $\mathrm{ZrO}_{2}$ ) system (i.e., during consecutive melting/solidification steps) ought to be further examined in order to test the thermal stability of reactively formed products. Our findings might provide a first indication in the selection of refractories for the PCM casing in Si-based LHTES device.

\section{SUPPLEMENTARY INFORMATION}

A fast-forward movie recorded during the wettability test is attached as the Supplementary Material 1.

\section{ACKNOWLEDGMENTS}

The project AMADEUS has received funds from the European Union's Horizon2020 research and innovation program, FET-OPEN action, under Grant Agreement 737054. The sole responsibility for the content of this publication lies with the authors. It does not necessarily reflect the opinion of the European Union. Neither the REA nor the European Commission are responsible for any use that may be made of the information contained therein. The authors acknowledge Mr M. Guaragno for his technical support concerning the XRD measurements.

\section{CONFLICT OF INTEREST}

The authors declare that there is no conflict of interests.

\section{OPEN ACCESS}

This article is distributed under the terms of the Creative Commons Attribution 4.0 International License (http://creativecommons.org/licenses/by/4.0/), which permits unrestricted use, distribution, and reproduction in any medium, provided you give appropriate credit to the original author(s) and the source, provide a link to the Creative Commons license, and indicate if changes were made.

\section{ELECTRONIC SUPPLEMENTARY MATERIAL}

The online version of this article (https://doi.org/10. 1007/s11661-018-5035-z) contains supplementary material, which is available to authorized users.

\section{REFERENCES}

1. Sh.A. Mohamed, F.A. Al-Sulaiman, N.I. Ibrahim, Md. Hasan Zahir, A. Al-Ahmed, R. Saidur, B.S. Yllbass, and A.Z. Sahin: Renew. Sust. Energ. Rev., 2017, vol. 70, pp. 1072-89, https:// doi.org/10.1016/j.rser.2016.12.012.

2. M. Liu, W. Saman, and F. Bruno: Renew. Sust. Energ. Rev., 2012, vol. 16, pp. 2118-32, https://doi.org/10.1016/j.rser.2012.01.020.

3. B. Cárdenas and N. León: Renew. Sust. Energy. Rev., 2013, vol. 27, pp. 724-37, https://doi.org/10.1016/j.rser.2013.07.028.

4. A. Datas, A. Ramos, A. Marti, C. del Canizo, and A. Luque: Energy, 2016, vol. 107, pp. 542-49, https://doi.org/10.1016/ j.energy.2016.04.048.

5. B. Drevet and N. Eustathopoulos: J. Mater. Sci., 2012, vol. 47, pp. 8247-60, https://doi.org/10.1007/s10853-012-6663-0.

6. Z. Yuan, W.I. Huang, and K. Mukai: Appl. Phys. A-Mater., 2004, vol. 78, pp. 617-22, https://doi.org/10.1007/s00339-002-2001-8.

7. W. Polkowski, N. Sobczak, R. Nowak, A. Kudyba, G. Bruzda, A. Polkowska, M. Homa, P. Turalska, J. Safarian, E. MoosaviKhoonsari, and A. Datas: J. Mater. Eng. Perform., 2017, https:// doi.org/10.1007/s11665-017-3114-8.

8. S.T. Mileiko: in Metal and ceramic based composites, Composite Materials Series, S.T. Mileiko, ed., 1997, vol. 12, pp. 233-305. https://doi.org/10.1016/s0927-0108(97)80023-9.

9. X. Duan, Z. Yang, L. Chen, Z. Tian, D. Cai, Y. Wang, D. Jia, and Y. Zhou: J. Eur. Ceram. Soc., 2016, vol. 36, pp. 3725-37, https:// doi.org/10.1016/j.jeurceramsoc.2016.05.007.

10. Henze HeBoSint Boron Nitride Products Overview: http://www.he nze-bnp.com/PDF/HeBoSint_PI_GB.pdf?m = 1502355729 accessed on $27 / 04 / 2017$.

11. L. Chen, Y. Wang, H. Shen, J. Rao, and Y. Zhou: Mater. Sci. Eng. $A$, 2014, vol. 590, pp. 346-51, https://doi.org/10.1016/ j.msea.2013.10.054.

12. X. Zhang, R. Zhang, G. Chen, and W. Han: Mater. Sci. Eng. A, 2008, vol. 497, pp. 195-99, https://doi.org/10.1016/ j.msea.2008.06.038.

13. Z.-H. Yang, D.-C. Jia, Y. Zhou, P.-Y. Shi, C.-B. Song, and L. Lin: Ceram. Int., 2008, vol. 34, pp. 317-21, https://doi.org/10.1016/ j.ceramint.2006.10.010.

14. J. Safarian, G. Tranell, and M. Tangstad: Enrgy Proced., 2012, vol. 20, pp. 88-97, https://doi.org/10.1016/j.egypro.2012.03.011.

15. N. Sobczak, R. Nowak, W. Radziwill, J. Budzioch, and A. Glenz: Mater. Sci. Eng. A, 2008, vol. 495, pp. 43-49, https://doi.org/ 10.1016/j.msea.2007.11.094

16. Y. Xu, T. Man, X. Wang, T. Jiang, and M. Yan: Ceram. Int., 2014, vol. 40, pp. 11171-76, https://doi.org/10.1016/ j.ceramint.2014.03.146.

17. N. Eustathopoulos: Curr. Opin. Solid. St. M., 2005, vol. 9, pp. 152-60, https://doi.org/10.1016/j.cossms.2006.04.004.

18. J. Roger, A. Marchai, and Y. Le Petitcorp: J. Cryst. Growth, 2015, vol. 426, pp. 1-8, https://doi.org/10.1016/j.jcrysgro.2015.05.013.

19. G.A. Yasinskaya: Sov. Powder. Metall., 1966, vol. 5, pp. 557-59, https://doi.org/10.1007/BF00780116.

20. J. Eichler and Ch. Lesniak: J. Eur. Ceram. Soc., 2008, vol. 28, pp. 1105-09, https://doi.org/10.1016/j.jeurceramsoc.2007.09.005.

21. W.-W. Wu, G.-J. Zhang, and Y. Sakka: J. Asian Ceram. Soc., 2013, vol. 1, pp. 304-07, https://doi.org/10.1016/ j.jascer.2013.08.002.

22. L. Chen, Y. Huang, Y. Wang, H. Shen, J. Rao, and Y. Zhou: Mater. Sci. Eng. A, 2013, vol. 573, pp. 106-10, https://doi.org/ 10.1016/j.msea.2013.02.063.

23. Ch. Yan, R. Liu, Ch. Zhang, Y. Cao, and X. Long: J. Am. Ceram. Soc., 2016, vol. 99, pp. 16-19, https://doi.org/10.1111/ jace. 14027.

24. A. Kumar, V. Thapliyal, D.G.C. Robertson, and J.D. Smith: $J$. Am. Ceram. Soc., 2015, vol. 98, pp. 1596-1603, https://doi.org/ $10.1111 /$ jace. 13492 .

25. A. Kumar, V. Thapliyal, and J.D. Smith: Int. J. Appl. Ceram. Technol., 2014, vol. 11, pp. 1001-11, https://doi.org/10.1111/ ijac. 12313 .

26. W.G. Fahrenholtz: J. Am. Ceram. Soc., 2005, vol. 88, pp. 3509-12, https://doi.org/10.1111/j.1551-2916.2005.00599.x.

27. A.W. Weimer: in: Carbide, Nitride and Boride Materials Synthesis and Processing, A.W. Weimer, ed., Springer, Netherlands, 1997, pp. 79-113. https://doi.org/10.1007/978-94-009-0071-4. 
28. L. Chen, Y. Wang, J. Rao, and Y. Zhou: Int. J. Appl. Ceram. Technol., 2015, vol. 12, pp. 184-91, https://doi.org/10.1111/ ijac. 1220 .
29. H. Kanai, S. Sugihara, H. Yamaguchi, T. Uchimaru, N. Obata, T. Kikuchi, F. Kimura, and M. Ichinokura: J. Mater. Sci., 2007, vol. vol. 42, pp. 9529-35, https://doi.org/10.1007/s10853-007-2090-z. 